\title{
Thermo in the Time of COVID-19: Using Improvisation to Foster Discussion and Translating the Experience to Online Learning
}

\author{
ERIN LAVIK (1) \\ Department of Chemical, Biochemical and Environmental Engineering, UMBC, Baltimore, Piscataway Territories, MD 21250, \\ USA
}

(Received 21 June 2020; accepted 23 August 2020; published online 2 September 2020)

\begin{abstract}
This paper covers teaching a graduate thermodynamics class as a seminar and using improvisational activities to foster community and discussion. The paper includes the experience of piloting improvisational activities online to help foster community for an entirely virtual version of the thermodynamics seminar class. Improvisational activities were found to help foster discussion in a thermodynamics seminar class, and some of these improvisational activities can be translated online in ways that may help to foster connection and community across the curriculum including online.
\end{abstract}

Keywords-Thermodynamics, Papers, Journal club, Discussion, Analysis of prior work, Community.

\section{CHALLENGE STATEMENT}

In 2019, I taught Thermodynamics for first year master's and $\mathrm{PhD}$ students in our program. Historically, the class was lecture based with problem sets and exams. One of the goals of the class is to help students apply thermodynamic concepts to their research and their future careers. One of the things I have observed in the oral qualifying exam is that some students struggle to make connections between their classes, their research, and the application of concepts in new forums. Furthermore, many first year students find it extremely challenging to speak in front of colleagues about topics and ask questions. Because I wanted to make more connections between the concepts and

Address correspondence to Erin Lavik, Department of Chemical, Biochemical and Environmental Engineering, UMBC, Baltimore, Piscataway Territories, MD 21250, USA. Electronic mail: elavik@umbc.edu research topics and projects the graduate students are interested in pursuing, I moved to a seminar model with presentation and discussion of recent papers with a strong thermodynamic focus.

However, it may not be surprising to hear that simply moving to a seminar structure did not trigger deep and meaningful conversations about thermodynamics. What did help trigger these conversations was doing improvisational exercises at the start of class. The impact was so strong that I carried it into my other classes. With the class being online this Fall, can we have meaningful conversations, dig into concepts, and build a community? The answer, I believe, is yes, and improvisation, I believe, is an important part of that answer, albeit it with a re-envisioning of the practice.

\section{NOVEL INITIATIVE}

\section{Implementing Improv in a Thermo Class}

Papers were selected at the beginning of the semester for the major topics covered in the class. During the first class, students were asked to provide suggestions for topics they would like to see covered. The topics and papers can be found in the syllabus and the document, ENCH-NEW-papers-questions in the supplementary information.

The seminar was organized so that there was a standard series of questions to guide the discussion coupled with specific questions presented the day before by the discussion leader. At the start of the class, students had 5-10 min to break into small groups and 
A

Improv exercises help me feel more alert

10 responses

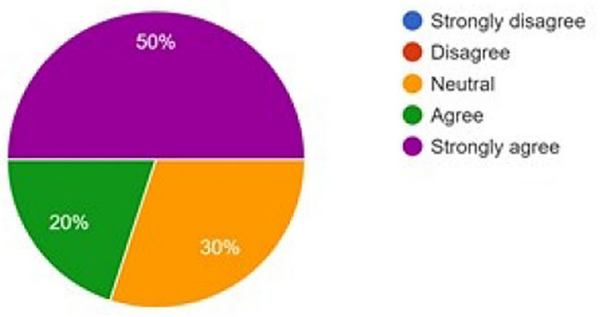

\section{C}

I can see the connection between Improv exercises and thermo 10 responses

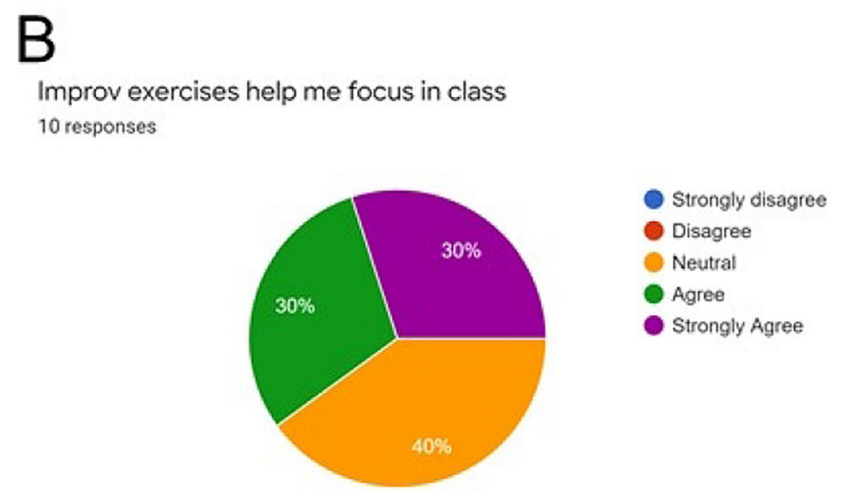
Do you want to continue doing improv exercises in class?
10 responses

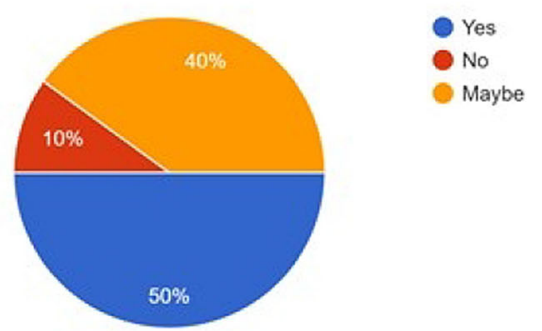

FIGURE 1. Students in the class were surveyed about the use of improvisational exercises. 10 of 16 students responded to the anonymous survey. (a) The majority of students agreed or strongly agreed that improv exercises made them feel more alert in class. (b) $60 \%$ of the respondents felt that improv helped them focus in class. (c) However, more than half were neutral or disagreed with there being a connection between improv exercises and thermodynamics. (d) Nonetheless, the majority wanted to continue the exercises.

focus on a subset of questions. We then came back as a full group and discussed the paper, the underlying thermodynamics, and the questions the paper raised.

One of the learning goals of the class was to understand the principles and applications of thermodynamics. My thought in moving this course to a seminar was so students could ask questions, be confused, and learn to help each other to be able to understand the concepts. It can be intimidating in a class to admit one is confused, and to search for help. This is magnified for international students.

The other two goals were to be able to critically analyze literature from the field and be able to write a compelling R21 style proposal that applies thermodynamics to an engineering problem. Both of these benefit from students being able to work together, talk openly, listen to each other, and help each other.

To help build an environment where students would feel safe asking questions, being wrong, and learning from each other, I turned to improvisational exercises. Improvisation requires deep engagement and active listening. ${ }^{1}$ It creates a framework that connects people. ${ }^{2}$ Assessments of using improvisation to improve science communication demonstrate that it improves the ability of scientists to connect with their audience and convey ideas more clearly than before they began improv exercises. ${ }^{3}$

Improvisation for scientists and engineers is not new. The Alan Alda Program for Communicating Science uses Improvisational Exercises as a core component of their training. Improvisational exercises improve scientists' ability to think on their feet ${ }^{4}$ and foster creative thinking ${ }^{5}$ and build confidence, ${ }^{4,6}$ resilience, ${ }^{7}$ and empathy. ${ }^{6,8}$ Improvisational exercises help to hone communication skills. ${ }^{8}$

Being able to communicate well has an important knock-on effect: it builds confidence. ${ }^{9}$ Knowing that one can improvise and think on one's feet reduces anxiety. ${ }^{9}$ Anxiety is cited as one of the factors that lead to almost $50 \%$ of students leaving without their PhDs. ${ }^{10}$

So, with this in mind, I selected some of the most traditional improvisational exercises including "Yes, and...", "experts", "the machine", and mirroring. At the start of half of the classes through the first half of the semester, we did an improv exercise. For the other 
half, we just started class. The non-improv start involved everyone breaking into 4 small groups to discuss the paper and write down their ideas and questions so they would feel prepared to discuss the paper in the larger group. I and the discussion leader would move between groups to answer questions and encourage them in the right direction.

\section{Improv Exercises and Ground Rules}

The ground rules for all of the exercises were to help each other, be patient, and there would no physical interaction. The improvisational exercises we used are outlined in Viola Spolin's Improvisation for the Theater, ${ }^{1}$, as well as Johnstone's Impro: Improvisation and the Theatre. "Yes, and" is the basis for all improv work. In the "Yes, and..." exercise, the first person in the group makes a statement. The second follows with "Yes, and..." and adds new information that exaggerates the statement. As each person takes a turn at contributing new information that builds on what has gone before, an imaginative narrative emerges. The affirmation and creative addition at the heart of the exercise foster a collective sense of play that is essential to collaboration and listening. ${ }^{11}$

In the experts exercise, a panel of experts is interviewed. They must respond as a group to a topic about which they have no experience. The activity hones the ability to think quickly and put together ideas in a way that sounds authoritative, which helps to build a sense of ease and confidence. ${ }^{1}$

In the machine exercise, each person does a movement and a sound. The next person comes in and builds on it until the whole group creates a machine of sound and movement. ${ }^{1}$ (for an example see: https:// www.youtube.com/watch?v = LSVGyaZNc10) This exercise was the least popular among the group based on the midpoint survey, because it was described as silly, which it definitely is. However, in the moment, it was the exercise that generated the most laughter of any exercise we performed.

\section{IMPACT ON DISCUSSION}

Prior to any surveys, a description of the surveys, the fact that they would be anonymous, and that they would ask questions regarding the methods in the class and whether they contributed to the student's sense of learning. The IRB committee performed an expedited review and found that it was not human subjects research UMBC Protocol \#: Y20EL26049.

Two weeks into the semester, students were given an anonymous survey regarding the class format. 6 students responded of 16 enrolled. All felt they were learning how to read scientific papers, but only $33 \%$ were confident that they were definitely learning thermodynamics and $50 \%$ felt like they were learning some thermodynamics. I needed to do better and help the students learn.

In half of the classes, we started with an improv exercise for the first 3-5 min followed by small group discussion. In the other half, we started with small group discussion. In classes where we moved directly into small group discussion, approximately $50 \%$ of the students did not speak in the large group. 4 of 16 students were strong participants speaking more than once during the discussion on a regular basis.

However, in classes where we started with an improvisational exercise, regardless of the exercise, every single person participated at least once with 8-10 participating two or more times per class. In a survey to the students given one month into the class, while many could not state whether there was a direct connect between improv and thermo, they all either agreed or strongly agreed with the statement improv helps me feel more engaged (Fig. 1).

\section{Impact on Applying Thermodynamics and Learning Goals More Broadly}

The three main learning goals of the class were to understand the principles and applications of thermodynamics, to be able to critically analyze literature from the field and to be able to write a compelling R21 style proposal that applies thermodynamics to an engineering problem.

One of the assessments of this was a score for the final R21 proposal as to whether thermodynamics was well-integrated in the proposal. One of the future assessments will be to look at how this score, for the class changes through the semesters. Two of the most critical assessments about the student's ability to learn and apply thermodynamics will occur during the qualifier exams and proposals which have not yet happened, but as part of our ongoing assessment of the program, we will be collecting this data.

\section{Moving Improv and the Thermo Seminar online}

Improv improved our class discussions. More people participated, more were willing to ask questions about concepts, and the environment was one where people supported and helped each other and felt connected. These aspects are more important than ever as we teach in a pandemic, so can it be moved online?

Gratefully, the answer is yes, but there are some steps needed to facilitate improvisation online. Technology matters. People need to have good headphones and a speaker to be able to communicate without too 
much feedback. To test how different improvisational exercises worked, I gathered six colleagues together to try out the exercises using Google Meet. Some had headphones, others did not. All had cameras on their devices. At the end of our exercises, we all agreed that a camera and headphones are essential for fostering participation.

The most successful exercise was experts. It was incredibly fun and well suited to the online environment. We had two experts, four reporters, and a moderator. It was clear that having a moderator who called on reporters who raised their hands was critical to people being able to hear and not talk over each other.

"Yes, and..." also worked well. We each held up a number so we knew the order. We found that we needed to go around twice to really get into the rhythm of the exercise. As one participant noted, the first time, they were focused more on who they followed than the story that was unfolding. Having a standard order might be helpful for this exercise. Both experts and "Yes, and..." can be performed without the need for cameras to allow students who either do not have cameras or who are uncomfortable turning them on to use only sound. In these cases, having a moderator or a planned order is essential for the improv exercises to progress effectively.

The machine did not work at all. As soon as multiple people started making sounds, the sound canceling software started to try and mute people and in the end, we only heard ourselves and not the larger group. It is not an accident that vocal groups record their parts separately. We were able to do a variant where people did a sound and movement and passed it to the next like "Yes, and..." It worked but was less fun than experts.

\section{REFLECTION}

\section{Building Community in Class}

The goal of the improvisational exercises was to reinforce the community of practice in the class as articulated by Wenger. ${ }^{12}$ Wenger argued that communities are critical to taking information and synthesizing it to build competence and become knowledgeable in an area. Wenger notes that how scientists communicate with colleagues to work through new theories and ideas is a prototypical community of practice. ${ }^{12}$ Communication and collaboration are critical to the science workplace of today. ${ }^{13}$ A number of groups have identified and studied these communities of practice in graduate programs, particularly in the biomedical sciences and found that practices such as problem-based learning not only lead to communities of practice, but that these communities carry over into other less formal learning opportunities through the curriculum building communities of practice throughout the graduate experience. ${ }^{14}$ Beyond the learning component, a sense of community plays a strong role in graduation rates across disciplines and plays a particularly important role in graduation rates in science and engineering, especially for underrepresented students. ${ }^{15}$

The positive reinforcement around improvisation exercises reinforces the community and sets a foundation for more discussion. ${ }^{16}$ The mantra of the class was that we are all in this together, and we help each other whether it is with thermodynamics, reading papers, writing proposals, or doing improv. One of the critical pieces of making this work is that I had to be as involved in all aspects as every other participant. The other aspect that was critical is that students were invited to participate. No one ever was required to do improv. It was important to make this clear at the start of each exercise.

The improv exercises often led to laughter, especially the exercises that were inspired by thermodynamics. We did a "Yes, and" based on the starting statement, "entropy is essential to understanding polymer behavior." We used our knowledge and found joy in applying it. We also had incredible laughter around the thermo machine. The first student came to the center and raised his hands and yelled, "Thermo!" Everyone improvised on it. Very few of the topics were science-oriented. We did exercises around the weather, holidays, the news, and being tired. The goal was to reinforce the community.

Not every student liked the improv exercises. While they were invited to participate, some did not enjoy it. In the assessment of using improv in the class, a number of students expressed frustration with improv component. 2 of 10 respondents disagreed or strongly disagreed with the statement, "I can see the connection between Improv exercises and thermo" (Fig. 1c). 1 of 10 respondents did not want to continue doing the exercises (Fig. 1d). Nonetheless 5 of 10 said yes to continuing and 4 of 10 said maybe with regards to continuing (Fig. 1d).

\section{Building Community Online}

Improvisation in a graduate thermodynamics class may sound silly, and it is, but, that silliness is the point. It helps to create an environment where it is ok to try out new ideas and experiment. It is easier to ask questions when people feel like they are part of a group. This is the essential concept in creating a community of practice. ${ }^{12}$ Fostering discussion online is 
challenges, but it is essential if our online learning is going to be able to be robust education. Based on my experience in the classroom and online, improvisation can help with that virtual community building that is essential for deep and thoughtful conversations. This aligns with previous work on building communities of practice in online formats, where one of the themes is that the group needs to have a shared purpose and interaction regardless of whether they are synchronous or asynchronous. ${ }^{17,18}$ Improvisation is a simple way to reinforce that shared purpose and interaction in a manner that helps foster discussion, which, in turn, should lead to deeper work exploring the concepts by the group.

\section{Shortcomings that Must Be Addressed Regarding Class Content}

One of the major shortcomings of the class is that we did not often dig as far into the papers as we wanted. I rescheduled the readings so we had classes to revisit papers, but this was far from ideal. In this first year of the new format, the class had three $50 \mathrm{~min}$ meetings per week which was rushed. We will have two 75 min meetings going forward which will help as we dig further into papers. Being online has a potential benefit, in that students can continue the discussion online outside of the synchronic portion of the discussion. The improv led to our wanting to talk with each other. The format now has more time to do so.

Another shortcoming was that while we covered papers on models, we did not, ourselves, work through the modeling. Being online invites the opportunity to work through the modeling as a community, and I think this is a critical part of increasing the depth we go into the concepts and work we cover in the class.

\section{Challenges with Improv and Seminar Format for Non-Native English Speakers}

At least three of the students in the class spoke English as a second language. Participating in a seminar is exceptionally challenging. Participating in improvisation in which one thinks on one's feet while the group is conversing in one's second language is extremely challenging. One student dropped the class, and they said it was because they found it challenging to follow and participate.

There are ways to make improvisation more inclusive. These methods can help to make space for students to be included more in a seminar. Certain improvisational activities, such as the machine, do not require one to listen or speak in a particular language. Often, sounds and gestures are used. In "Yes, and" allowing the pace to slow and having the group cele- brate each addition helps to include members who are struggling or worried about their speech. The sense of waiting, celebrating, and supporting sets up a culture that is carried into the discussion of papers.

These challenges are only magnified working online. Drawing on improv exercises that are not dependent on speech such as those that use sounds and motion versus words and stories can be a strong place to start, especially for non-Native speakers. One of the classic improvisational exercises that we did not do in thermodynamics that would work online is the name exercise. A person says their name and makes a sound and motion. The next person repeats the first persons name, sound and motion, and then does their own. The third person does the names, sound and motion of the second person, then adds their own. It can be a strong icebreaker during early classes that is less storydriven that experts or even "Yes, and...".

\section{Assessing Outcomes}

For those who are interested in implementing improv and want to assess outcomes, the ones I have found during my pilot that seem the most important are: a survey that asks students about their impressions of improv and impact on their desire to speak in class as well as their sense of being part of a cohort, student participation, ability to analysis literature in the discipline (which I do as part of the grading of the final proposals), and application of concepts to new research which is also assessed during the final proposals.

\section{CONCLUSIONS}

Moving to a seminar format did help students see the applications of thermodynamics concepts in new ways. Learning to discuss concepts and work together to try and understand unfamiliar concepts or applications is a skill set that I anticipate will stay with the students beyond the class. Doing an activity like improvisation helped the students create a place in the classroom where they laughed and started to know each other. Moving this online will, hopefully, help the students develop connections with each other in spite of the distance between them. Hopefully, too, it will help them find joy and laughter in a time where the pandemic and desperate need to address structural racism is incredibly weighty. Laughter fosters breathing, and deep breaths are important in our classes right now. 


\section{ELECTRONIC SUPPLEMENTARY MATERIAL}

The online version of this article (https://doi.org/10. 1007/s43683-020-00022-z) contains supplementary material, which is available to authorized users.

\section{ACKNOWLEDGMENTS}

I am extremely grateful to Kath Bogie, Dawn Taylor, Lynn Watson, Stian Rice, Adrienne Wheeler, and Ranee Mehra for testing out improvisational exercises online.

\section{REFERENCES}

${ }^{1}$ Spolin V. Improvisation for the theater: a handbook of teaching and directing techniques. Evanston: Northwestern University Press; 1983.

${ }^{2}$ Alda A. If I Understood You, Would I Have This Look on My Face?: My Adventures in the Art and Science of Relating and Communicating. New York: Random House; 2017.

${ }^{3}$ Ponzio NM, et al. Learning science communication skills using improvisation, video recordings, and practice, practice. Practice J Microbiol Biol Educ. 2018. https://doi.org/ 10.1128/jmbe.v19i1.1433.

${ }^{4}$ Shochet R, et al. 'Thinking on my feet': an improvisation course to enhance students' confidence and responsiveness in the medical interview. Educ Prim Care. 2013;24(2):11924.

${ }^{5}$ Pfeiffer FM, et al. When theater comes to engineering design: Oh How Creative They Can Be. J Biomech Eng. 2017;139(7):071004.

"Gao L, et al. The role of "improv" in health professional learning: a scoping review. Med Teach. 2019;41(5):561-8.
${ }^{7}$ Fanian S, et al. Evaluation of the Kots'iihtla ("We Light the Fire") Project: building resiliency and connections through strengths-based creative arts programming for Indigenous youth. Int $\mathbf{J}$ Circumpolar Health. 2015;74:27672.

${ }^{8}$ Kaplan-Liss E, et al. Teaching medical students to communicate with empathy and clarity using improvisation. Acad Med. 2018;93(3):440-3.

${ }^{9}$ Bernstein R. Communication: spontaneous scientists. Nature. 2014;505(7481):121-3.

${ }^{10}$ Paul Barreira P, Basilico M, Bolotnyy V. Graduate student mental health: lessons from American Economics Departments. Cambridge: Harvard University; 2018.

${ }^{11}$ Johnstone K. Impro: improvisation and the theatre. London: Routledge; 2012.

${ }^{12}$ Wenger E. Communities of practice: learning, meaning, and identity. Cambridge: Cambridge University Press; 1999.

${ }^{13}$ Ferrini-Mundy J. Science education. Driven by diversity. Science. 2013;340(6130):278.

${ }^{14}$ Orsmond P, Zvauya R. Community of learners: charting learning in first year graduate entry medical students during problem-based learning (PBL) study. Adv Health Sci Educ Theory Pract. 2015;20(2):479-97.

${ }^{15}$ Main, J.B., Kanter's Theory of Proportions: Organizational Demography and $\mathrm{PhD}$ Completion in Science and Engineering Departments. Research in Higher Education, 2018.

${ }^{16}$ Rossing JP, Hoffmann-Longtin K. Improv(ing) the academy: applied improvisation as a strategy for educational development. Improv Acad. 2016;35(2):303-25.

${ }^{17}$ Schwier RA, Balbar S. The interplay of content and community in synchronous and asynchronous communication: virtual communication in a graduate seminar. Can J Learn Technol. 2002;28(2):21-30.

${ }^{18}$ Putz P, Arnold P. Communities of Practice: guidelines for the design of online seminars in higher education. Educ Commun Inf. 2001;1(2):181-95.

Publisher's Note Springer Nature remains neutral with regard to jurisdictional claims in published maps and institutional affiliations. 